\title{
TRADE DRESS, IMAGEN EMPRESARIAL O APARIENCIA DISTINTIVA: COMO OBJETO DE PROTECCIÓN DENTRO DE UNA FRANQUICIA *
}

\section{Trade dress, enterprise image or distinctive appearance: as an object of protection within a franchise}

Isabel Cristina García Velasco**

Universidad del Valle. Santiago de Cali, Colombia.

Recepción: 21 de febrero de 2017. Aceptación: 21 de marzo de 2017.

DOI: http://dx.doi.org/10.21017/Rev.Repub.2017.v22.a27

\section{RESUMEN}

Este artículo se inserta dentro de la propiedad industrial y uno de los signos de mayor reconocimiento son las marcas, las cuales pueden diferir según las personas a las que beneficia, por su forma o percepción.

No obstante, cada vez la imagen de los productos, de los establecimientos de comercio, es más importante y forma parte de los mismos, tanto la calidad como la manera de proyectarse y de ser reconocidos dentro del consumidor y público en general, lo cual se conoce como trade dress (apariencia distintiva, imagen comercial). Esta categoría ha sido protegida en muchas legislaciones de origen continental como marca, sin embargo, el derecho anglosajón le otorga una categoría de protección en la propiedad industrial de manera específica diferente a la marca. Entonces, dentro del contexto jurídico colombiano: ¿podría protegerse de manera individual al trade dress? toda vez que esta

* Artículo producto de la línea de investigación Política comercial y derecho de propiedad intelectual del grupo de investigación Derecho, Sociedad y Estado (GIDSE) de la Facultad de Ciencias de la Administración de la Universidad del Valle.

** Abogada Universidad de San Buenaventura Cali. Especialista en Derecho Comercial Universidad Pontificia Bolivariana de Medellín en convenio con la Universidad de San Buenaventura Cali. Magister en Derecho Comercial Universidad Sergio Arboleda - Bogotá. Doctoranda en Derecho Universidad Sergio Arboleda - Bogotá. Docente de carrera de la Universidad del Valle. Investigadora Grupo de Investigación Derecho, Sociedad y Estado, Universidad del Valle. Miembro del Instituto de Responsabilidad Civil y del Estado de Cali. Correo electrónico: Isabel.c.garcia@correounivalle. edu.co 
categoría adquiere importancia no solo a nivel individual sino que dentro de los contratos de franquicia es un elemento a tenerse en cuenta al momento de realizarse la operación contractual.

Se utilizó una metodología descriptiva, para analizar la protección de esta institución dentro del derecho continental, la cual eventualmente puede protegerse como diseño industrial o marca tridimensional. Se muestra como resultado que en Colombia el trade dress (apariencia distintiva, imagen comercial), no es objeto de protección de manera específica a pesar de ser parte integrante de los productos y establecimientos de comercio en el país, y que deberían ser protegidos como otra categoría diferente a la marca en los contratos de franquicia.

Palabras clave: propiedad intelectual, propiedad industrial, marcas, trade dress, franquicia.

\section{ABSTRACT}

This article is inserted within the industrial property and one of the signs of greater recognition are the marks, which can differ according to the people to whom it benefits, by its form, perception.

Nonetheless, the image of products and commercial establishments is increasingly important and part of them is the quality and the way they are projected and recognized within the consumer and the general public. What is known as trade dress, distinctive appearance, commercial image, this category has been protected in many laws of continental origin as a brand. However, Anglo-Saxon law grants a category of protection in industrial property in a specific way, different from the mark. Then, within the Colombian legal context: could the trade dress be protected individually? Since this category acquires importance not only at the individual level but within the franchise agreements is an element to be taken into account at the time of the contractual operation.

A descriptive methodology was used to analyze the protection of this institution within continental law, which protects it as a trademark. It is shown as a result that in Colombia the trade dress, distinctive appearance, commercial image is not subject to specific protection despite being an integral part of the products, establishments of commerce in the country and should be protected as a category other than the Brand in franchise contracts

Keywords: intellectual property, industrial property, trademarks, trade dress, franchise. 


\section{INTRODUCCIÓN}

Este artículo de reflexión es el resultado de un proyecto de investigación de la propiedad industrial en Colombia, deriva como en los establecimientos de comercio, los productos, su imagen o apariencia aportan a estos unas características que los hacen únicos y conforman una individualización dentro de los restantes de su mismo género. Es lo que se conoce como trade dress o imagen comercial, apariencia distintiva. En el derecho internacional, específicamente en el derecho basado en el common law, no solo las marcas son objeto de protección legal también los diseños de los establecimientos comerciales, vestuario de los empleados, disposición de los productos, mercancías que se colocan a disposición de los consumidores.

La protección de esta imagen comercial o trade dress, en derechos como el colombiano, todavía no es objeto de protección, sino que se incluye dentro de la protección marcaria tridimensional, diseño industrial y hasta como competencia desleal. El interés académico surge, toda vez que la comercialización de productos y marcas dentro del contexto de la globalización e internacionalización de la economía, se constituye en una forma de llegar a nuevos mercados y por ende consumidores, por medio de los contratos de franquicia. Constituye un problema jurídico, analizar el concepto de trade dress, evolución, características y cómo puede ser objeto de protección en un contrato de franquicia la presentación, apariencia o en palabras sencillas el "vestido" del negocio o producto. En ese orden de ideas la pregunta a resolver desde la propiedad industrial es: ¿puede el trade dress, ser objeto de protección jurídica además de lo que involucra la marca o servicio a franquiciar?

La metodología utilizada correspondió al método cualitativo, con base en revisión de literatura gris, artículos en revistas indexadas para describir concepto, características del trade dress, y normas nacionales e internacionales, comunitarias para determinar ámbito de protección en otras legislaciones de esta institución como fuentes primarias y fuentes secundarias de doctrina y resoluciones de la Superintendencia de Industria y Comercio entre otras.

Entre los resultados obtenidos está que en Colombia, dentro de las instituciones que conforman la propiedad industrial, el concepto de trade dress, no es objeto de protección jurídica al igual que en países vecinos al nuestro, que a pesar de referir en algunas legislaciones a la apariencia del producto no son protegidos como una categoría distinta al producto, por la tradición jurídica del derecho continental, contrario sensu, al derecho norteamericano, que sí reconoce y protege jurídicamente la institución jurídica del trade dress. 
Como sugerencia de este artículo, en un mundo donde el comercio impone dinámicas de comercializar productos o servicios bajo la experticia de los propietarios de los mismos por medio del auge de las franquicias, indistintamente que sea reconocido o no por la legislación colombiana, el trade dress, va a tener que protegérsele, dentro de alguna de las categorías de la propiedad industrial, bien como parte de los elementos que conforman la marca o bien como diseño industrial, lo cual conceptuó la superintendencia de industria y comercio (SIC) en Colombia.

\section{FUNDAMENTACIÓN CONCEPTUAL DEL TRADE DRESS}

El trade dress o imagen comercial, hace parte de la propiedad industrial ${ }^{1}$. La institución que abarca a la propiedad industrial es la intelectual que consagra una protección sobre bienes tangibles e intangibles. La propiedad industrial desarrolla la protección de patentes, marcas, diseños industriales, circuitos integrados entre otros. Elementos intangibles que son de gran valoración cuantitativa como cualitativa en el mundo empresarial, toda vez que en la actualidad puede costar mucho más los intangibles de una sociedad comercial que el conjunto de maquinarias, materias primas, etc. Esta dinámica varía por los cambios en los modelos para realizar negocios. La internacionalización de la economía produce que se pase de la interdependencia económica de los estados a la movilidad de los negocios, esto acarrea una heterogeneidad de la economía mundial. Por ende ya los productos como bienes y servicios siguen siendo importantes pero a partir del "consenso de Washington"2 ; modelo aceptado hasta $2008^{3}$, el comercio internacional gira hacia las redes (comercio electrónico) y se desplaza la transferencia de las mercancías físicas, caracterizándose por el protagonismo de los servicios frente a la mercancía, con esto la OMC, otorga especial atención a los servicios y a la propiedad intelectual (Fernández et. al, 2009, pp. 31-33).

1 La institución de la P.I., se divide en dos categorías, como lo define la Organización Mundial de la Propiedad Intelectual (OMPI): 1) los derechos de propiedad industrial y, 2) los derechos de autor. Esta clasificación se complementa con otras dos, que comprende 3) los derechos derivados de los obtentores vegetales y 4) derechos del acceso a los recursos genéticos, como lo conceptúa la Comunidad Andina de Naciones (CAN), que involucra las cuatro categorías.

2 Fernández (2009) refiere que dicha formulación es de J. Williamson del Institute for International Economics, entre cuyos postulados están: disciplina presupuestaria, cambios en los gastos públicos, liberalización financiera, liberalización comercial, entrada de inversiones extranjeras, privatizaciones y garantías de los derechos de propiedad.

3 Fernández (2009) señala que en el 2008, se presentó la crisis económica en EE.UU. cuando cayeron los precios de las viviendas, crisis financiera y créditos, subida del euro. 
Es así como la institución de la propiedad intelectual e industrial se convierten en ventaja competitiva en el mundo de los negocios. La imagen corporativa o trade dress, no es la excepción, es un aspecto importante la forma como se aproxima y caracteriza un producto, establecimiento de comercio al consumidor final, que hasta el momento en la economía colombiana, se subsume su protección desde lo Marcario ${ }^{4}$.

Diferente a otras legislaciones como las basadas en el common law, donde esta percepción visual de los negocios se convierte en un punto de protección disímil a la marca.

El trade dress o imagen comercial o vestir visualmente, se ha convertido en una ventaja competitiva entre los diferentes productos, establecimientos de comercio; con lo cual se pretende innovar y atraer la clientela, donde la parte externa o visual, el desarrollo arquitectónico, el vestido de los empleados, formas de distribución de las góndolas con los productos y demás formas de decoración, de ambiente, se conviertan en un distintivo para el consumidor final y si bien la calidad de los productos son importantes al igual que el servicio, este sello personal marca una diferencia visual y es lo que crea unidad de negocio, aspecto que las franquicias cuidan al entregar un negocio.

\subsection{Trade dress. Concepto y características}

El trade dress, imagen comercial, vestido comercial o estilo comercial entre muchas otras acepciones, se define como "la imagen, impresión o apariencia total o global de un producto o servicio" concepto de Ludwig et al. (Berger, 2008), para otros autores como Daher (2005) (Superintendencia de Industria y Comercio, 2005) lo definen como:

4 Tal como lo expone la Superintendencia de Industria y Comercio (SIC) en Colombia en su concepto 06007139 y lo ratifica en el concepto 05015398: las disposiciones contempladas en la Decisión 486 no regulan expresamente la figura del "trade dress", como tampoco la de los elementos que la conforman. No obstante, como veremos, algunos de tales elementos pueden ser considerados, y por lo tanto registrados, como signos distintivos o como nuevas creaciones (...) De la definición expuesta acerca del significado del "trade dress" se desprende que algunos de los elementos que conforman la presentación externa de un producto o establecimiento comercial, podrían eventualmente asociarse con la figura de una marca (tridimensional) comercial o de un diseño industrial. No obstante, como es de su conocimiento, solamente la oficina competente, esto es la Delegatura de Propiedad Industrial de esta Superintendencia, podrá, previo estudio y una vez realizado el procedimiento conducente, pronunciarse sobre la registrabilidad o no de un signo distintivo o de una nueva creación que sea presentada para su registro, de acuerdo con el procedimiento para ello establecido. 


\begin{abstract}
"suma de elementos decorativos y de presentación que identifican un producto o establecimiento, que en su conjunto generan la existencia de una percepción por parte del consumidor al confrontarlos. En caso de los establecimientos participan como elementos de "trade dress" los colores empleados, los elementos ornamentales, la disposición de anaqueles, los menús, la vestimenta de los empleados, la iluminación, los letreros del lugar, su arquitectura, etc. En el caso de los productos participan elementos tales como el tamaño y la forma de los empaques y los envases, los colores usados, el tipo de letras, las leyendas genéricas, y en general, la combinación de elementos que visualmente identifican el producto".
\end{abstract}

Tinoco Soares (2000), lo define como "medio por el cual un producto es presentado al mercado".

La International trademark Association (INTA) conceptúa:

“el trade dress es la imagen de un producto que los diferencia de los demás, hace parte de este concepto, la forma, etiqueta, envase de un producto; la decoración del lugar donde se presta el servicio. El trade dress puede consistir en tamaño, forma, color, textura siempre que no sean elementos funcionales. En algunos países puede ser conocido como puesta en marcha o diseño de producto". (traducción propia) ${ }^{5}$

La imagen comercial o estilo comercial o trade $d_{r e s s}{ }^{6}$, es una concepción del derecho norteamericano. Surge por la competencia desleal entre empresarios ${ }^{7}$. Los cuales tratan de soportar sus nuevos negocios o productos con la imagen o forma que otra persona ha realizado. Este concepto de proteger la imagen o vestido de un producto o servicio, está ampliamente regulado en el derecho

5 Refiriéndose al texto de la International Trademark Association (2012): trade dress is the overall commercial image (look and feel) of a product that indicates or identifies the source of the product and distinguishes it from those of others. It may include the design or shape/configuration of a product; product labeling and packaging; and even the décor or environment in which services are provided. Trade dress can consist of such elements as size, shape, color and texture, to the extent that such elements are not functional. In many countries, trade dress is referred to as "get-up" or "product design.

6 Pueden encontrarse diversas acepciones como ropaje comercial, apariencia distintiva, imagen de marca, imagen empresarial.

7 Tobón (como se citó en Tribunal de Justicia de la Comunidad Andina, 2014) determinó que el trade dress se puede proteger en Colombia a través de las acciones por competencia desleal, inclusive aunque no exista una marca registrada previamente, puesto que lo que se busca es evitar que sucedan actos capaces de crear confusión por cualquier medio respecto del establecimiento, producto o actividad de un competido. 
norteamericano, contrario sensu de los países como Colombia, el cual maneja todo lo referente a la propiedad industrial bajo la Decisión Andina 486 del año 2000 y no incluye protección, ni regulación al trade dress.

Sin embargo, según la Superintendencia de Industria y Comercio (2005) el concepto trade dress, trae consigo elementos de presentación de un producto o establecimiento que podría ser asociado con la figura de marca comercial o diseño industrial y podría protegerse como una marca siempre que cumpla con los requisitos de distintividad, perceptibilidad, susceptibilidad de representación gráfica ${ }^{8}$.

Como se colige, sobre el tratamiento jurídico a la figura del trade dress, cada legislación le da un marco de protección diferente, si bien Norteamérica lo reconoce, otros países lo protegen como marcas, diseño industrial o competencia desleal por lo que no hay una uniformidad en su manejo jurídico.

El trade dress, es el conjunto de elementos como colores, arquitectura, vestimenta de los empleados, iluminación, distribución de anaqueles los que conforman el estilo comercial o apariencia de un producto o un establecimiento de comercio que aportan una distintividad en el consumidor final. Aspectos que son percibidos primero por el consumidor aún antes de conocer el producto o establecimiento. Toda vez que hace referencia a su apariencia, embalaje, colorido lo cual es captado visualmente.

Con base en lo anterior el trade dress, puede ser objeto de protección, según la superintendencia de Industria y Comercio (2005), como marca tridimensional $^{9}$

8 Con base en el concepto de la SIC de abril 2005 0514398, (...) las Oficina de Marcas y Patentes de Colombia (Superintendencia de Industria y Comercio) ha afirmado que sus elementos se pueden proteger a través de la figura de la marca comercial tridimensional 1, el diseño industrial 2 o, inclusive, la posibilidad de interponer acciones por competencia desleal derivadas de actos de engaño, de confusión y de imitación.

9 Como lo explica Rey-Alvite (2014) el empleo más habitual de la marca tridimensional consiste en el registro como marca de la forma tridimensional del envase, botella, contenedor, envoltorio y demás medios de presentación comercial del producto designado...Por último, que no menos importante, debe tenerse en cuenta que existe una gran variedad de productos que carecen de una forma definida por sí mismos, requiriendo de algún tipo de envase o embotellamiento para su comercialización. Este es el supuesto de los productos consistentes en fluidos de diversa naturaleza, como zumos, perfumes, geles o cremas. En el caso de estos productos resulta imposible jugar con la forma del producto para diferenciarlo en el mercado, por lo que se potencia la figura del envase como elemento de distintividad, adquiriendo este un especial valor económico y comercial. 
Entendiéndose como marca en el sentido estricto, signo distintivo que caracteriza productos, servicios, establecimientos de comercio para distinguirse en el mercado ${ }^{10}$, pero como además también pueden conformar la marca la forma de sus productos, envases, envolturas es lo que se conoce como marca tridimensional ${ }^{11}$. No obstante, como manifiesta el profesor Cornejo Guerrero (2011, p. 87), respecto a las marcas tridimensionales:

"pese a la utilidad de la definición de marca tridimensional referida, hay que notar que ella solo comprende a las formas tridimensionales del mismo producto o su envase; y en consecuencia cierra la posibilidad de que formas tridimensionales que no sean las de los mismos productos 0 sus envases, puedan ser marcas".

Con lo cual, también es complejo que el trade dress, pueda ser protegido con todo lo que incluye la figura del trade dress, como marca tridimensional.

De otra parte, también puede protegerse el trade dress como diseño industrial, según el artículo 113 de la Decisión Andina 486 del año 2000 que lo define como:

"la apariencia particular de un producto que resulte de cualquier reunión de líneas o combinación de colores, o de cualquier forma externa bidimensional o tridimensional, línea, contorno, configuración, textura o material, sin que cambie el destino o finalidad de dicho producto" (DA, 486-2000).

De igual manera, existen otras posiciones como el tratadista americano Stephen P. Ladas citado por Pérez(2011), en su libro "Patents, Trademarks and Related Rights: National and International Protection, que el trade dress, puede ser objeto de protección mediante Derecho de autor ${ }^{12}$, cuando es una creación artística y original.

10 El Instituto Nacional de Propiedad Industrial estipula que al empresario la marca comercial le permite desarrollar su estrategia de competitividad y forjar su prestigio e identidad empresarial. Las marcas pueden ser palabras, etiquetas, tipos de intangibles protegidos por la Propiedad Intelectual y áreas en que se subdivide.

11 Entendida por Cornejo (2011) como la marca tridimensional es aquella forma tridimensional que sirve para identificar y diferenciar productos o servicios de sus similares en el mercado. Ella puede consistir en formas particulares de los productos, sus envases, envoltorios, empaques o recipientes en general; en formas tridimensionales que distingan productos, pero que no consistan en la forma de los mismos, o en formas tridimensionales aptas para distinguir servicios de sus similares en el mercado.

12 Al respecto, Pérez (2011) refiere otros inconvenientes como lo complicada que resulta la presentación de las pruebas de la paternidad de la obra en caso de litigio. 
Si bien aquí en Colombia no se tiene protegida la figura del trade dress, si puede asegurarse que esta institución forma parte de los signos distintivos y por ende de la propiedad industrial y como conceptúa la Superintendencia de Industria y Comercio (SIC) puede ser objeto de protección como marca tridimensional, diseño industrial y por competencia desleal, lo cual se tratará infra.

\subsubsection{Orígenes, protección y características de la institución trade dress}

El trade dress, surge en Norteamérica, hace cien años, como referencia a la presentación de un producto por su envoltura, etiqueta o envase. Glen, Wadyka, Jacobs y Lee, citado por Berger(2008), afirman que: «"históricamente, el trade dress, se refería solo a la forma en que un producto era "vestido para salir al mercado". Con el correr del tiempo el concepto de trade dress se fue expandiendo, pudiendo incluirse en él a la forma básica de un producto, su packaging y su apariencia general».

Según Pérez Suárez (2011) el origen del trade dress, puede ubicarse ciento sesenta años atrás: «Já Pouillet ha dejado constancia que supone tal antigüedad en uno de sus apuntes judiciales de 1835, en el mismo siglo XIX, sobre actos de competencia desleal por confusión de un "trade dress"... Emplear para la venta un producto similar, de la misma forma y el mismo color de la caja de la casa competidora. (Trib. Comm. Sena, 17 sept.1835, Gevelot, gás. Trib., 18 sept)» (p. 30).

Para el derecho Norteamericano, si es objeto de protección como institución jurídica, mediante Lanham Act de $1946^{13}$, sección 43, apartado a) se protege la imagen de los productos, envase y la presentación del acondicionamiento de un producto, servicio ${ }^{14}$.

La naturaleza jurídica del trade dress en Colombia, aún no está definida, sin embargo, puede protegerse como marca, diseño industrial luego en el derecho

13 La International Trademark Association (2012) refiere: in the United States, trade dress, like a trademark, is protectable under the federal Trademark Act (Lanham Act). If the trade dress is unregistered, the first hurdles that the trade dress owner must clear are articulating which aspects of its product or packaging constitute trade dress and establishing that the trade dress is protectable.

14 Harmon (como se citó en Internacional Trademark Association, 2012) señala: specifically, Section 43(a) of the Lanham Act provides a cause of action to anyone who is likely to be damaged when another person uses in commerce any "word, term name, symbol, or device, or any combination there of... which is likely to cause confusion... as to the origin, sponsorship, or approval of ... her goods. 
continental, se puede ubicar dentro de los signos distintivos ${ }^{15}$ en la propiedad industrial, cabe aclarar que en la Decisión Andina 486 de 2000, esta figura no se encuentra establecida. Como manifiesta Jalife Daher (2013) es necesario que los productos, servicios, establecimientos de comercio se identifiquen entre la competencia y para el consumidor y esto se logra mediante el empleo de signos distintivos como marca, aviso, nombre comercial.

No obstante es oportuno mencionar que si bien la figura del trade dress, puede protegerse mediante «diseño industrial, marca tridimensional» (Superintendencia de Industria y Comercio, 2005) también es posible su protección mediante la Ley 256 de $1996^{16}$, que contempla lo referente a la competencia desleal ${ }^{17}$ entre los cuales están los actos de desviación clientela, desorganización, confusión, engaño, descredito, comparación, imitación, explotación de la reputación ajena, violación de secretos, inducción ruptura contractual, violación de normas, pactos desleales de exclusividad; en ese orden de ideas cualquier imitación al trade dress o apariencia distintiva de un productos (envase) o de un establecimiento de comercio puede ser objeto de protección mediante esta norma, como se puede referir a la reproducción de la forma del envase, colores que puede inducir al cliente final a error en la escogencia del producto, bien lo refiere sentencia 2762 de la Superintendencia de Industria y Comercio (SIC) donde argumenta «modificó sustancialmente su etiqueta reproduciendo "en forma idéntica" elementos esenciales de la presentación comercial o "trade dress" de "Girasoli", tales como los colores, disposición de diseños y el tipo y tamaño de letras, elementos que, si bien la parte actora reconoció como comunes en la categoría, afirmó que fueron dispuestos de tal forma que generó confusión entre los consumidores» (p. 1).

\subsubsection{Características del trade dress}

Ya se ha analizado el concepto del trade dress, pero cuáles son sus principales características, si se tiene en la cuenta que esta institución hace referencia a la imagen, forma, colores, uniformes de empleados, disposición de góndolas en un establecimiento de comercio y como manifiesta Contreras (2011) «...la disposición de los cubiertos, la disposición de los elementos en una etiqueta; las

15 La Superintendencia de Industria y Comercio (2012) señala: de la definición expuesta a cerca del significado del "trade dress" se desprende que algunos de los elementos que conforman la presentación externa de un producto o establecimiento comercial, podrían eventualmente asociarse con la figura de una marca (tridimensional) comercial o de un diseño industrial.

16 Artículos 7 al 19 sobre actos de competencia desleal de la referida.

17 Al respecto véanse sentencia No. 2762 de 31 de mayo de 2012 y concepto 06007139 del 09 de marzo de 2006 de la Superintendencia de Industria y Comercio. 
técnicas de ventas y cualquier otro elemento que identifique visualmente al producto o servicio».

Con base en lo desarrollado y teniendo en cuenta que se trata de un signo distintivo se podría mencionar que dentro de las características del trade dress, se pueden referir:

A. El trade dress, forma parte de la apariencia de los productos, establecimientos de comercio. Pueden identificarse elementos como los colores, formas, texturas, aromas, ubicación de luces, góndolas, uniformes de los empleados, arquitecturas, diseños de ambientes que caracterizan y marcan diferencia final para la identificación y escogencia del consumidor final en lo referente a los productos y establecimientos de comercio.

B. Se puede colegir y los doctrinantes sobre la materia, enfatizan, que el trade dress, no forma forma parte de la funcionabilidad del producto, como se hace referencia en las traducciones de esta acepción significa la apariencia externa de los productos y establecimientos de comercio.

C. El trade dress, debe ser de uso constante y continuo para poder crear dentro del consumidor un referente que lo haga único entre otros productos similares.

Lo anterior se colige con base en lo tratado por el profesor Harmon Cooley (2008, p. 28) sobre el caso Taco Cabana International, Inc. y Taco Cabana, Inc. demandaron al restaurante Two pesos ${ }^{18}$ donde la Corte Norteamericana sostiene:

«The Court determined that "trade dress that is inherently distinctive is protectible under $\S 43$ (a) without a showing that it has acquired secondary meaning". The Court further explained that suggestive, arbitrary, or fanciful marks, "because their intrinsic nature serves to identify a particular source of a product, are deemed inherently distinctive and are entitled to protection". The Court continued its analysis of distinctiveness by elucidating that "the general rule regarding distinctiveness is clear: An identifying mark is distinctive and capable of being protected if it either (1) is inherently distinctive or (2) has acquired distinctiveness

18 Fue un caso que estuvo en la Corte Norteamericana, en el cual se discutía si el restaurante Two Pesos, Inc., que operaba en Houston, había copiado mucha de la apariencia de otro restaurante llamado Taco Cabana. En 1987, esta última demanda al restaurante Two Pesos Inc., en la corte de Texas (Legal Information Institute, 1992). 
through secondary meaning". Finally, the Court reaffirmed the wellestablished principles that "eligibility for protection under $\S 43(a)$ depends on nonfunctionality" and that "liability under $\S 43$ (a) requires proof of the likelihood of confusion".»

Así las cosas, el trade dress, es apariencia distintiva que implica la forma, aspecto; bien, del producto bien, del establecimiento de comercio.

\subsubsection{Trade dress en otras legislaciones}

Ya se ha manifestado que, en el derecho colombiano, esa figura no está contemplada y por ello se plantea protegerla por medio de marca tridimensional, diseño industrial, competencia desleal.

No obstante, es una figura del derecho norteamericano, que, aunque no lo protege directamente si protege a sus marcas por medio de Lanham Act de 1946, cuyo principal objetivo es proteger las marcas, uso indebido, falsificación de las mismas y por ende al consumidor, como lo establece el título 15 de la referida ley y la institución del trade dress, ha sido protegida vía jurisprudencial además de que se basa en lo referente, sección 43 , apartado a) de la ley referida.

Pero igualmente en países que no tienen sus orígenes en el common law, se protege esta institución, se hace referencia:

\section{Ecuador}

País perteneciente a la Comunidad Andina, con la Ley de Propiedad Intelectual (LPI No 83), en la cual define el concepto de trade dress, pero referido a los establecimientos de comercio, es el único país que define esta institución.

Art. 235: «Se considera apariencia distintiva todo conjunto de colores, formas, presentaciones, estructuras y diseños característicos, y particulares de un establecimiento comercial, que lo identifiquen y distingan en la presentación de servicios o venta de productos».

Berger (2008, p. 61) manifiesta en Ecuador, se registra, son los elementos que conforman la apariencia distintiva pero los elementos como uniformes a pesar de considerarlos que forman parte del trade dress, se registran como marca.

\section{Panamá}

Ley 35, de 10 de mayo de 1996, en su artículo 90 establece: 


\section{"Las formas tridimensionales, incluidos los envoltorios, envases, la for- ma del producto o su presentación y hologramas".}

De igual manera, reconoce dentro de su legislación la forma de los productos, aunque no hace referencia a las presentaciones de los establecimientos de comercio.

\section{México}

En el derecho mexicano, no existe una norma positiva sobre protección del trade dress, sin embargo la segunda sala de la Suprema Corte de Justicia de la Nación, tesis aislada 2a. LXVII/2015 (10a.) derecho a la imagen comercial en $2015^{19}$, analiza los nuevos alcances de la protección del trade dress en México como consecuencia de la Tesis Aislada así como una comparación con la protección del trade dress en los Estados Unidos de América (Ishbak y Sánchez, 2016).

Si bien con estos casos, se demuestra que a pesar de que en algunos países comienza a ser reconocida la figura del trade dress, también es cierto que falta una normativa más específica sobre la materia, en países de tradición diferente a la norteamericana.

\section{TRADE DRESS, COMO SIGNO DISTINTIVO.}

Teniendo en cuenta que el trade dress, podría en Colombia protegerse como signo distintivo o marca. Por eso es necesario precisar, como manifiesta Pachón

19 La Suprema Corte de Justicia de la Nación (2015) plantea que el derecho a la imagen comercial o «trade dress» es una derivación del derecho de propiedad industrial y es entendida como la pluralidad de elementos que, como consecuencia de su combinación, permite distinguir productos o servicios, representando una ventaja competitiva en virtud de la identificación generada, y la titularidad de ese derecho se encuentra protegida en la fracción XXVI del artículo 213 de la Ley de la Propiedad Industrial, en tanto prohíbe usar la combinación de signos distintivos, elementos operativos y de imagen, que permitan identificar productos o servicios iguales o similares en grado de confusión a otros protegidos por el ordenamiento referido, que por su uso causen o induzcan al público a confusión, error o engaño, por hacer creer o suponer la existencia de una relación entre el titular de los derechos protegidos y el usuario no autorizado. Esto es, la fracción aludida sanciona como infracción administrativa las conductas que por el uso de la combinación de ciertos elementos -imagen comercial- lleven al público consumidor a asociar un producto o servicio con otros protegidos por la propia ley o a suponer la existencia de una relación entre el titular del derecho y quien presume serlo sin tener un justo título. 
(1984), que los derechos de propiedad industrial, pueden clasificarse en tres grupos:

1. Derechos sobre creaciones nuevas. Otorgan a su titular la facultad exclusiva de explotarlos por un espacio determinado. Comprenden patentes de invención, modelos y dibujos industriales.

2. Los signos distintivos. Indagan sobre ciertas ventajas en la búsqueda y mantenimiento de una clientela mediante la utilización de símbolos que permiten identificar al fabricante, productos, origen. Este grupo comprende marcas, nombres comerciales, enseñas, denominaciones de origen, indicaciones de origen.

3. Represión de la competencia desleal. Con ella se busca señalar normas de comportamiento para los comerciantes y reprimir abusos de los excesos de competencia.

Los signos distintivos, son aquellos que identifican a una empresa, productos, servicios entre los cuales se encuentran las marcas, nombre comercial, lema comercial, enseña, indicaciones geográficas, denominaciones de origen. Los derechos sobre los signos distintivos son maneras de obtener ventajas en la búsqueda y mantenimiento de una clientela mediante la utilización de símbolos que permitan identificar al fabricante, establecimiento, productos o el origen de estos (Pachón, 1984, p. 1). Por su parte, Castro García (2009, p. 41), sostiene que los signos cumplen un rol primordial en el funcionamiento de la economía; permiten dentro del mercado distinguir y diferenciar productos o servicios (marcas, lemas comerciales, nombre de dominio) establecimientos de comercio (por medio de nombre comercial y enseña) o el origen, modos de producción o fabricación de productos por medio de las indicaciones geográficas. De ahí el concepto reiterativo de la Superintendencia de Industria y Comercio (SIC) de que el trade dress, pueda recibir protección bajo la figura del signo distintivo y más en nuestro derecho que no contempla dicha figura y si analizamos la institución jurídica de las marcas, estas representan un activo importante para la empresa, toda vez que denota calidad de los productos. La marca es un signo visible que se coloca sobre el producto o que se relaciona con un producto o un servicio y está destinado a distinguir los productos o servicios de un empresario (Pachón, 1984, p. 1).

Asimismo la marca tiene una función clásica como es que el consumidor diversifique a los diferentes competidores en el mercado e igualmente una función esencial, que permite la identificación del origen de los productos que consume; como también una función publicitaria o de comunicación ya que la marca puede transmitir una imagen de la empresa que fabrica los productos o 
suministra los servicios marcados, una función de garantía de buena calidad, esta se cumple en el caso de las marcas de certificación, como lo manifiesta Castro García (2009, pp. 66-68).

El trade dress, al no contar con una particular protección por parte de la Decisión Andina 486 del año 2000 de la Comunidad Andina, bien puede protegerse bajo una de estas categorías, toda vez que se ha analizado, que esta figura contiene la identificación de un producto sin que esa forma, color, textura haga parte de la funcionabilidad del producto ya que es accesoria, pero lo identifica y lo hace único para el consumidor final, que lo distingue de otros similares, razón por la cual el derecho norteamericano lo protege ${ }^{20}$ toda vez que como país cuya economía se basa en el consumo, estos elementos bien sea de un producto o un establecimiento de comercio merecen toda su protección legal porque es una manera de comunicar y establecer vínculos sensoriales con el consumidor final. Ahora bien, porque el trade dress, ¿también está relacionado con los establecimientos de comercio? Porque a nivel del derecho comercial colombiano, según el artículo 516 del Código de Comercio, es parte del establecimiento de comercio la enseña, mobiliario, instalaciones, a lo cual hace alusión el concepto del trade dress, según las concepciones sobre esta figura. Contribuyen a aportar a la identificación sensorial de dicho lugar bien por su olor, vestido de los empleados, forma de las letras, hasta como se sirven las comidas, bebidas, etc., dentro del consumidor que hace que lo prefiera por encima de una gran variedad de sitios con similares servicios pero que por su forma, le aporta dicha unicidad al negocio. Como afirma el profesor J. Thomas McCarthy, el cual define el trade dress como la totalidad de elementos que forman un producto o un servicio y que combinados crean un conjunto visual para ser presentado a los consumidores, del cual pueden adquirirse derechos en exclusiva como un tipo de marca o un símbolo de identificación del origen empresarial (Pérez Suárez, 2011, p. 25).

Con base en lo expuesto se puede afirmar que en «Colombia todavía no se vislumbra una protección exclusiva para el trade dress y en la jurisprudencia

20 Refiriéndose al texto, Harmon (2008) señala: (...) the Supreme Court has outlined several key elements for a finding of unregistered trade dress protection. First, these cases reinforce the "well-established rule that trade dress protection may not be claimed for product features that are functional. Further, the current state of Lanham Act jurisprudence clearly holds that there will be trade dress protection for product design only upon a showing of secondary meaning (indicating that the trade dress has acquired distinctiveness which serves to identify the product with its manufacturer or source). Secondary meaning "occurs when in the minds of the public, the primary significance of a [mark] is to identify the source of the product rather than the product itself. 
colombiana cuando se evalúa el trade dress, nos encontramos con que el juez o examinador no se concreta en establecer si se presentó la reproducción en cuestión, sino en determinar si esa circunstancia constituye, efectivamente o potencialmente, el acto desleal de confusión». En cuanto al trade dress para que este sea protegido debe darse lo siguiente: «a) Que el conjunto de elementos que conforman la apariencia general del producto sea único e inusual en el campo particular. b) Debe ser identificatorio y distintivo para que sea protegible. c) Que no constituya un simple refinamiento de una comúnmente adoptada y bien conocida forma de ornamentación para una clase particular de productos. d) Que sea capaz de crear una impresión comercial distinta de la parte denominativa. e) Que el empaque pueda indicar el origen del producto». (Suárez, Cendoya, García, 2013, p. 7, 8).

Lo cierto es que ya sea la forma de la botella, envoltura, etc. del producto, permite al consumidor identificarlo sobre otros similares «permiten a los consumidores, a cierta distancia identificar el producto sin necesidad de ver la marca en sí (Pérez Suárez, 2011, p. 25). La apariencia de las envolturas en los productos son objeto de protección, pero se ha visto que igual la forma, diseño, iluminación, arquitectura, uniformes de un establecimiento de comercio, también ha sido objeto de protección de esta institución jurídica trade dress; no en vano casos del derecho norteamericano como «Las vaqueritas de Dallas», las edificaciones de Fotomat Corporation han sido protegidas por medio del trade dress (Pérez Suárez, 2011, p. 25). En ese orden de ideas, en Colombia, en un contrato de franquicia: ¿los elementos decorativos deben ser objeto de protección?

\section{TRADE DRESS. UNIDAD DE NEGOCIO EN LAS FRANQUICIAS}

\subsection{Concepto contrato de franquicia o franchising}

El contrato de franquicia, es un contrato de comercialización y distribución de productos y/o servicios, propio del contexto internacional económico, el cual se define como un acuerdo entre dos partes independientes, mediante el cual una de las partes, quien ha logrado un éxito comercial en un área específica de negocios, otorga a cambio de cierta remuneración económica, el derecho a utilizar su nombre comercial, marca y saber-hacer empresarial a la otra parte quien actúa bajo su propio riesgo, por un tiempo limitado y en un territorio determinado. Básicamente contiene el otorgamiento de un Know How y una licencia de marca. Este contrato se desarrolla en el derecho norteamericano en el siglo XIX, cuando la Singer otorgó franquicias a comerciantes independientes para comercializar sus productos (Marzorati, 2011, p. 223, 225, 268). 
Es un contrato por medio del cual puede iniciarse una empresa, negocio propio sin mayor riesgo en la inversión, toda vez que se apalanca en la experiencia de otro comerciante que ha sido exitoso en ese negocio ${ }^{21}$. Como manifiesta Marzorati (2011, p. 237) «la mayor parte de los convenios en los países industriales de Occidente, mediante los cuales un productor de bienes o servicios faculta a un tercero a comercializarlos, caen dentro de la definición de la franquicia».

En Colombia no existe una tipificación o regulación expresa del contrato de franquicia, pero basados en la Constitución Política, que permite la libertad en actividades económicas e iniciativas privadas, siempre y cuando no contraríe normas imperativas de orden público y las buenas costumbres, es posible su celebración.

La franquicia o franchising, como se le conoce es una de las formas de concesión y es definida por Guyénot en Arrubla (2006) como la concesión de una marca de productos o de servicios a la cual se agrega la concesión del conjunto de métodos y medios de venta. Así «Cualquier empresa que goce de un adecuado posicionamiento en su entorno de actuación, y que cuente con ciertas perspectivas de crecimiento, no puede dejar de ver en la franquicia una de las alternativas más rentables y eficaces para la consecución de todo objetivo relativo a la cobertura de nuevos mercados» (Mosquera Muñoz, 2010, p. 71).

De igual manera, autores como Guyénot (1973, p. 161) sostiene que entre la franquicia y concesión comercial, no existe diferencias y en palabras del autor que refiere Marzorati (2011, p. 244) en su obra Sistemas de Distribución Comercial, «la franquicia no sería otra cosa que una forma de concesión comercial, calificada con una terminología propia, pero sin significación jurídica; sería

21 Según Gananci.com (2016) entre las franquicias de más bajo coste en Colombia, se puede referir: Doctor Solución (franquicia en Colombia de origen brasileño, trabaja en el sector de la prestación de servicios de reparaciones de albañilería, pintura, plomería y electricidad). Carolina Cruz Accesorios (lleva ya funcionando en el país más de 5 años. Los principales productos de este negocio son accesorios, artículos de salud y belleza, calzado y marroquinería). Prontowash (empresa de origen argentino, modelo de negocio. Consiste en el lavado de vehículos de forma ecológica). D-uñas (empresa española. Proporcionan servicios de esmaltado permanente, uñas esculpidas, manicura y pedicura, pero también realizan trabajos de limpiezas faciales, depilación, o colocación de extensiones de pestañas postizas). Supercoffe (empresa nacida en Colombia. Su modelo de negocio son minimáquinas automáticas de café destinadas a colocarse en empresas y otros negocios donde los visitantes, empleados y clientes necesiten tomarse una buena taza de esta rica bebida). Club de viajes Believe (principales funciones de las franquicias Relieve, son prestar servicios para organizar y vender paquetes turísticos nacionales e internacionales). 
una misma sustancia contractual bajo términos equivalentes... en el contrato de franquicia el tomador está obligado a pagar un derecho de ingreso al sistema y cuotas periódicas, mientras que los contratos de concesión rara vez prevén tales obligaciones».

Según el autor Kahn referido Marzorati (2011) pueden existir diversos tipos de franquicia como puede ser la franquicia industrial, ejemplo este, las embotelladoras, caso Coca Cola o Pepsi, franquicia de distribución de un bien, franquicia de servicio, p.e. caso Ren a car, franquicia hotelera, p.e. Holiday Inn.

\subsection{Características del contrato de franquicia o franchising}

En la franquicia es usual el derecho de entrada y de regalías para el franquiciante ${ }^{22}$ y de derechos a explotar un establecimiento de comercio, una marca, un nombre y recibir un Know How, para el franquiciado. El éxito del franquiciado es el éxito del franquiciante, lo que se traduce en una asistencia técnica permanente y en un control ejercido sobre el franquiciado a fin de que se ajuste a lo pactado. El franquiciado no está subordinado jurídica ni económicamente al franquiciante, sino que actúa a nombre propio asumiendo los riesgos de la inversión necesaria para la instalación del establecimiento y desarrollo de la actividad, y comprometiendo en ello su patrimonio.

Es así como se infiere que dentro del contrato en el cual se otorga el derecho a utilizar su nombre comercial, marca y saber-hacer empresarial a la otra parte quien actúa bajo su propio riesgo, por un tiempo limitado y en un territorio determinado, está implícito otorgar también la forma o imagen del producto o establecimiento de comercio, como manifiesta Arrubla Paucar (2006, p. 337) «el franquiciador cede los medios para comercializar los productos o servicios convenidos».

Entre las características del contrato de franquicia, las ramas del derecho cuya aplicación se deben tener principalmente en cuenta son el derecho laboral, el derecho de marcas, el derecho fiscal, el control de cambios y el derecho de la competencia a lo que debe agregarse la transferencia de tecnología y las locaciones comerciales. Entre los elementos básicos de la franquicia se encuentran: licencia de marca, territorio, operador de franquicia, transferencia del know how.

22 Los sujetos dentro de este contrato son: franquiciante o franquiciador, que es la empresa propietaria del nombre comercial, la imagen, marca o signos distintivos y los conocimientos. Franquiciado: es el inversor quien adquiere la utilización de estos activos para vender, distribuir o explotar comercialmente y bajo su propio riesgo, durante un tiempo determinado y un lugar o territorio preestablecido uno o varios productos o servicios. 
La franquicia además de tratar cada una de estas instituciones jurídicas, el licenciamiento de marca implica: «usar siempre la marca del franquiciante, utilizar signos distintivos y seguir las instrucciones del manejo de las mismas, toda vez que la licencia es acompañada de una serie de normas con relación al modo en que debe actuar el franquiciado en el desempeño de sus actividades y en la administración de los productos de la marca, como manifiesta el profesor Marzorati (2011, p. 241, 251).

Como puede observarse, la marca en el contrato de franquicia es un elemento básico al igual que su manejo y las instrucciones respecto al manejo de la misma; luego con base en lo anterior, el trade dress, en el contrato de franquicia debe ser objeto de protección y debe de establecerse una protección a esta institución (trade dress) que aunque poco protegida en otras legislaciones, ya comienza a buscarse diferentes formas de protección, y para un comerciante es esencial que se le otorgue un manejo igual al que le da el franquiciador a su marca.

En el contrato de franquicia la forma de presentación del producto, establecimiento de comercio debe quedar estipulado no solo en la parte del manejo marcario sino todo lo que supone el concepto del trade dress; ya que el franquiciante quien es titular de una marca y otros signos distintivos, mediante este contrato autoriza al franquiciado la utilización para vender bienes y/o servicios con ella. «La diferencia básica entre la franquicia y la concesión: el concedente entrega la distribución, la marca, licencias, al concesionario; en la franquicia, aparte de esto, se entrega un concepto de negocio, un sistema completo de gestión llamado técnicamente Business Format Franchising, que en su conjunto pretende garantizar el éxito. La asistencia y el control son completos y permanentes. Por lo anterior, el sistema empresarial de franquicia es más que un sistema de distribución, dado que abarca toda la línea integral desde su conceptualización; incluye, en algunos casos, desde la fabricación hasta la postventa al cliente final» (Mosquera Muñoz, 2010, p. 75-76).

Dicha autorización es limitada y está sujeta a una serie de restricciones, solo puede ser utilizada con lo que es el objeto de la franquicia, en el local o establecimiento de comercio que se haya seleccionado para desarrollar la actividad del negocio, no podrá estar acompañada de otras marcas o símbolos, y solo podrá ser utilizada en el territorio y durante el tiempo designado en el contrato, para que no se presenten casos de infracción a la imagen comercial, por una utilización indebida de decoración, arquitectura del vestido comercial o trade dress. Toda vez que el carácter de distintividad es la que otorga ese carácter de unicidad que dentro de un contrato de franquicia también debe formar parte y ser protegido. 
Lo anterior, supone que es la franquicia un negocio de pagar el derecho de poder utilizar una marca, pertenece a un tercero, con todo lo que implica el concepto marcario.

\subsection{Trade dress y su relación con el contrato de franquicia}

Como se ha tratado supra, el objeto de contrato dentro de una franquicia es finalmente la comercialización de la marca, ya sea de un producto o servicio. La cual servirá de apalancamiento para la inversión del futuro franquiciado, quien adquiere el derecho de explotar la marca.

Es así como en la negociación de esta clase de contratos es importante delimitar todo lo relativo a la propiedad industrial entendiéndose no solo la marca, lema comercial, sino los elementos del trade dress, los cuales forman parte de la presentación del producto y de los establecimientos de comercio.

Por tanto, en el contrato de franquicia se debe establecer una cláusula además de la licencia de marca, que explicite la no modificación y protección de la apariencia distintiva, trade dress del producto o establecimiento de comercio. Teniendo en cuenta que como en Colombia, no existe dentro de las categorías de la propiedad industrial, puede ser susceptible de copia por los competidores, por eso es importante que la Superintendencia de Industria y Comercio (SIC), por lo menos ha reiterado en sus conceptos que si bien no está protegida como categoría de la propiedad industrial puede ser objeto de protección mediante marca tridimensional, diseños industriales y por el tema de competencia desleal, tratado supra dentro de este artículo.

Es por la vía de la competencia desleal, en un momento dado, que podría entrar a defenderse el dueño de la marca, no obstante, las probabilidades son reducidas porque esta categoría no está reconocida. Sin embargo, de entrar a demostrar que se está engañando y utilizando otra forma distintiva perteneciente al franquiciador, podría ser objeto de protección, mediante los artículos 7 a 19 sobre actos de competencia de la Ley 256 de 1996, entre los cuales cabe referir:

Actos de desviación clientela, desorganización, confusión, engaño, descrédito, comparación, imitación, explotación reputación ajena, violación secretos, inducción ruptura contractual, violación de normas, pactos desleales de exclusividad.

Por lo anterior, un empresario dueño de una marca que pretenda franquiciar y como se refirió el elemento básico es la licencia de marca en el contrato de franquicia, perfectamente podría proteger además de su marca registrada, todo 
lo que encierra la misma, es decir, etiqueta, forma, textura de los envases y si se trata de establecimientos de comercio, incluir disposición de anaqueles, uniformes, iluminación, distribución de mesas, forma de organizar y presentar los productos, hasta olores aromatizantes, pueden incluirse.

Igualmente el franquiciador tiene la facultad de entregar instrucciones, normas en la forma como debe de ser utilizada la marca y todos los elementos que la conforman. Lo importante es que si bien esta figura no está protegida en el ordenamiento jurídico colombiano, la idea es crear consciencia entre los empresarios, académicos, que más allá de la marca cualquiera sea su clasificación (mixta, colectiva, certificación, notoria) como signo distintivo de un producto o servicio, lo importante es tener claro que si bien el registro de la marca es importante dentro de la empresa, también lo es la forma de presentación, colores, letras y para el caso de los establecimientos de comercio, su iluminación, uniformes, mesas, mobiliario, decoración que si efectivamente no tiene relevancia en la funcionabilidad de dicho producto o establecimiento de comercio, si lo diferencia entre los consumidores y se vuelve hasta referencia para identificarlo entre otros similares que ofrece el mercado.

Para el caso de la negociación de una franquicia se considera que, dentro del elemento básico del uso de licencia de marca, para el franquiciado debe estructurarse una entrega total de normas y reglas para su uso, que incluya los elementos descritos dentro del trade dress, objeto también de protección legal.

No obstante, supra, se había referido que el trade dress, podría ser protegido también como derecho de autor, es otra opción muy viable que en el derecho mexicano se ha considerado, toda vez que el trade dress o apariencia distintiva de los establecimientos de comercio, no solo incluye mobiliario, luces, estantes y demás objetos decorativos sino también diseños arquitectónicos, por ser obras de arte aplicadas: «en el establecimiento de un negocio sujeto a franquicia se podrán encontrar infinidad de elementos creativos puramente ornamentales y aplicados a objetos funcionales o utilitarios, y la fachada y demás elementos arquitectónicos originales del establecimiento de la franquicia también podrían merecer la protección que brinda el derecho de autor. Las obras arquitectónicas constituyen una especie más de las obras de arte aplicado en general. Sin embargo, en este caso existen varios aspectos que podrían ser objeto de protección, a saber: planos, escrituras, ornamentos y demás elementos decorativos del edificio arquitectónico» (Schmidt, 1990). Si bien esta es una opción de protección para que el franquiciador pueda proteger su apariencia distintiva, si debe tenerse en cuenta que dichos diseños no estén relacionados con la funcionalidad del producto o servicio, aspecto que caracteriza al trade dress. 


\section{COMENTARIOS FINALES}

Entre los hallazgos encontrados en el presente artículo, cabe referir:

1. El trade dress o imagen del producto o vestimenta del establecimiento, puede aplicarse bien para productos o establecimientos de comercio. Dentro de las características del trade dress, se puede inferir que este ropaje o imagen comercial no forma parte del producto en sí o que sea funcional del mismo sino meramente un aspecto decorativo y que entregue una vinculación sensorial con el consumidor final que lo diferencie de otros productos o establecimientos similares sin dar lugar a una confusión.

2. El derecho norteamericano, reconoce la figura del trade dress, toda vez que busca que este se convierte en un elemento distintivo de los productos, establecimientos de comercio que los hace diferentes a otros similares y crea un vínculo entre el producto, lugar o espacio físico y los consumidores.

3. La figura del trade dress, es protegida en legislaciones como la norteamericana; países como Colombia, no tiene dentro de la propiedad industrial, la protección jurídica de esta figura. No obstante puede llegar a protegerse como marca tridimensional, diseño industrial y como competencia desleal. Ecuador es uno de los países que si protege esta figura pero solo para establecimientos de comercio.

4. En Colombia la institución del trade dress, se otorga mediante la protección de marcas, diseños industriales o competencia desleal, pero no como figura jurídica independiente toda vez que la Decisión Andina 486 del año 2000, no la regula.

5. Si bien la apariencia distintiva, trade dress, no ha sido muy desarrollada en países como el nuestro, si es necesario incluirlo como otra categoría dentro de la protección de la propiedad industrial por su relación con la marca de productos o servicios.

6. Otra forma de proteger el trade dress, es por medio de los derechos de autor, otorga derechos para poder utilizarlos por terceros, lo cual podría ser de gran seguridad para el franquiciador con relación a su diseño o apariencia, siempre que no tenga relación con la funcionabilidad del producto.

7. El contrato de franquicia, es una forma de distribuir, comercializar productos en el contexto global de la economía, mediante el uso de marca, el saber hacer, el cual se le entrega a un tercero. En ese orden de ideas para el consumidor final es transparente quien es el dueño, lo que sí le interesa es 
que el producto o establecimiento de comercio, sea idéntico al inicial y es en ese aspecto donde no solo el contrato implica uso de la marca, sino todos los elementos que hacen único y diferente a los productos o establecimientos de otros similares.

8. En el contrato de franquicia la forma de presentación del producto, establecimiento de comercio debe quedar estipulado no solo en la parte del manejo marcario sino todo lo que supone el concepto del trade dress; ya que el franquiciante quien es titular de una marca y otros signos distintivos, mediante este contrato autoriza al franquiciado la utilización para vender bienes y/o servicios con ella.

9. El contrato de franquicia debe de establecer una cláusula además de la licencia de marca, que explicite la no modificación y protección de la apariencia distintiva, trade dress del producto o establecimiento de comercio. Así, en legislaciones como la nuestra no esté protegido dentro de la propiedad industrial, la protección del trade dress, si es necesario incluirlo como otra categoría dentro de la protección de la propiedad industrial por su relación con la marca de productos o servicios.

10. Los contratos de franquicia, son contratos atípicos pero por lo mismo debe de contemplarse dentro del contrato un punto referido al trade dress, toda vez que el franquiciante quien es titular de una marca y otros signos distintivos, mediante este contrato autoriza al franquiciado la utilización para vender bienes y/o servicios, y los elementos decorativos, ambientación que dan lugar a la forma del producto o establecimiento de comercio, si debe estar protegido así no sea como la figura del trade dress, si mediante otra categoría diferente a la marca, para de esta forma proteger legalmente a la forma como a la distinción del bien o producto en el mercado y evitar en un futuro competencias desleales.

\section{REFERENCIAS}

Arrubla Paucar, J. A. (2006). Contratos mercantiles Tomo III, contratos atípicos. $6^{\mathrm{a}}$ ed. Medellín: Editorial Biblioteca Jurídica Diké.

Berger, F. (2008). La apariencia distintiva (trade dress): un signo marcario en expansión (tesis de maestría). Universidad de Palermo, Buenos Aires, Argentina.

Contreras, A. M. (2011). Las creaciones gastronómicas como objeto de protección por el Derecho de Autor: posibilidades y conveniencia siguiendo el enfoque de la propiedad Intelectual y la competencia desleal (tesis de maestría).Pontificia Universidad Católica del Perú, Lima, Perú. 
Castro García, J. D. (2009). La propiedad Industrial. Bogotá: Universidad Externado de Colombia.

Fernández, J. C., Arenas, R., de Miguel Asencio, P. A. (2009). Derecho de los negocios internacionales. $2^{\mathrm{a}}$ ed. Madrid: Iustel.

Guyénot, J. (1973). Le franchise commerciale - étude compare des systèmes de distribution interentreprises constitutif de groupements de concessionnaires. Revue trimestrielle de Droit Commercial, tome 26.

Jalife Daher, M. (2013). Competencia desleal: régimen jurídico mexicano. México: Porrúa.

Marzorati, O. (2011). Sistemas de distribución comercial. Buenos Aires: Editorial Astrea.

Mosquera Muñoz, F. (2010). La Franquicia una estrategia de crecimiento empresarial. Revista MBA EAFIT, dic., (1):70-85.

Ortiz de Zarate, A. (1998). Manual de la franquicia. Madrid: Ed. Tormo \& Asociados.

Pachón Muñoz, M. (1984). Manual de propiedad industrial. Bogotá: Temis.

Pérez Suárez, M. C. (2011). El “Trade Dress”. Puntos de vista acerca de esta figura. Revista de la Red de Expertos Iberoamericanos en Propiedad Industrial, (8):24-34.

\section{Bibliografía electrónica}

Cornejo Guerrero. C. A. (2011). La marca tridimensional. Santiago de Chile: Universidad Bernardo O'Higgins. Recuperado de http://www.ubo.cl/icsyc/wp-content/ uploads/2011/10/3-Cornejo.pdf

Harmon Cooley, A. (2008). Trade dress protection of business décor: what is this thertium quid? Southern Law Journal, 18, 19-43. Recuperado de http:// www.southernlawjournal.com/2008/02_.pdf

International Trademark Association. (2012). Fact ships types of protection. Washington: INTA. Recuperado de http:/ / www.inta.org/TrademarkBasics/FactSheets/ Pages/Trade-Dress.aspx

Ishbak González, A. y Sánchez Duro, D. D. (2016). La protección de la imagen comercial o 'trade-dress' en México. León, Guanajuato: Mipatente.com. Recuperado de http:/ / www.mipatente.com/la-proteccion-de-la-imagen-comercial-o-trade-dress-en-mexico/

Gananci.com. (2016). Las mejores franquicias en Colombia. Cali: Gananci.com. Recuperado de http:/ / gananci.com/franquicias-en-colombia/ 
Rey-Alvite Villar, M. (2014). El carácter distintivo de la marca tridimensional en la jurisprudencia de la unión europea. Cuadernos de Derecho Transnacional, 6 (1), 294329. Recuperado de http://e-revistas.uc3m.es/index.php/CDT/article/ download/1919/912

Schmidt, L.C. (1990). Breve análisis sobre las franquicias y el derecho de autor. Revista Mexicana del Derecho de Autor, año 1, (3), jul.-sep. Recuperado de http:// www.olivares.com.mx/En/Knowledge/Articles/CopyrightArticles/Breve AnlisissobrelasFranquiciasyelDerechodeAutor

Suárez, E., Cendoya, S. García, M. (2013). Un acercamiento a la protección jurídica del trade dress en Colombia. Una mirada a la luz del derecho comparado. Medellín: Universidad Pontificia Bolivariana. Recuperado de https://repository.upb.edu.co/ bitstream/handle/20.500.11912/1511/Proteccio\%CC\%81n\%20al\%20Trade\%2 0Dress. \%20Trabajo\%20final\%20Seminario\%20de\%20Investigacio\%CC\%81n.pdf? sequence $=1 \&$ is Allowed $=y$

Tinoco Soares, J.C. (2000). "Concorrencia desleal vs trade dress" e/ou "conjunto-imagem" (visual do objeto, do produto, de sua exteriorizacao e do establecimento. Sao Paulo: Ed. Do Autor. International Trademark Association. Recuperado de inta.org/Trademark Basics/FactSheets/Pages/Trade-Dress.aspx

\section{Códigos y leyes}

Colombia. Asamblea Nacional Constituyente (1991). Constitución Política de 1991. Gaceta Constitucional, No. 116, 20 de julio de 1991. Bogotá: Secretaría del Senado. Recuperado de http://www.secretariasenado.gov.co/index.php/constitucionpolitica

Colombia. Presidencia de la República (1971). Decreto 410, por el cual se expide el Código de Comercio. Diario Oficial, No. 33339, 16 de junio de 1971. Bogotá: Alcaldía de Bogotá. Recuperado de http://www.alcaldiabogota.gov.co/sisjur/normas/ Norma1.jsp?i=41102

Colombia. Congreso de la Republica (1996). Ley 256, por la cual se dictan normas sobre competencia desleal. Diario Oficial, No. 42692, 18 de enero de 1996. Recuperado de http://www.secretariasenado.gov.co/senado/basedoc/ley_0256_1996.html

Comunidad Andina de Naciones. (2000). Decisión 486, régimen común sobre propiedad industrial. La cual establece el marco legal de propiedad intelectual para los países que la integran: Colombia, Venezuela, Ecuador, Perú y Bolivia. Lima: CAN. Recuperado de http://www.wipo.int/edocs/lexdocs/laws/es/can/can012es.pdf 
Estados Unidos de Norteamérica. Lanham Act de 1946. The primary federal trademark statute of law in the United States. Recuperado de http:/ / www.uspto.gov/sites/ default/files/trademarks/law/Trademark_Statutes.pdf

Ecuador. Congreso de la República (1998). Ley No. 83, ley de propiedad intelectual. Registro Oficial, No. 320, 19 de mayo de 1998. Recuperado de http:/ / www.wipo.int/ edocs/lexdocs/laws/es/ec/ec001es.pdf

Panamá. Asamblea Legislativa. (1996). Ley No. 35, por la cual se dictan disposiciones sobre la propiedad industrial. Gaceta Oficial, No. 23036, 15 de mayo de 1996. Recuperado de http:/ / www.wipo.int/wipolex/es/details.jsp?id=3387.

\section{Sentencias}

Tribunal de Justicia de la Comunidad Andina (2014). Proceso 234-ip-2013. M.P. Luis José Diez Canseco Núñez Interpretación prejudicial del artículo 136 literal a) de la Decisión 486 de la Comisión de la Comunidad Andina; y, de oficio, de los artículos 134 literales a), b) y g), 137 y 150 de la misma normativa; con fundamento en la solicitud formulada por la Octava Sala Especializada de lo Contencioso Administrativo de la Corte Superior de Justicia de Lima, República del Perú. Marca: "TUCO BATÁN" (mixta). Expediente Interno: 04675-2010-0-1801-JR-CA-15. Recuperado de intranet.comunidadandina.org/ documentos/Procesos/234-IP-2013.doc.

Tribunal de Justicia de la Comunidad Andina (2014). Proceso 66-ip-2014. M.P. José Vicente Troya Jaramillo. Interpretación prejudicial a petición del juez consultante de los artículos 134, 136 literal a) y 137, correspondientes a la Decisión 486 de la Comisión de la Comunidad Andina y de oficio, literales a), b), f) y g) del artículo 134, artículos 258 y 259 de la Decisión 486 de la Comisión de la Comunidad Andina. Órgano nacional consultante: Consejo de Estado de Colombia. Demandante: Harinera del Valle S.A. Demandado: Superintendencia de Industria y Comercio de la República de Colombia (SIC) Asunto: Marca: "Zonia (mixta)". Expediente Interno: 2012-00314. Recuperado de http:// intranet.comunidadandina.org/Documentos/Procesos/66-IP-2014.docx

Superintendencia de Industria y Comercio (2012). Sentencia No. 2762 (31 de mayo). Superintendencia de Industria y Comercio, delegatura para asuntos jurisdiccionales en la acción de competencia desleal promovida por Team Foods Colombia S.A. y Grasas S.A. (en adelante: Team y Grasas) contra Lloreda S.A. (en adelante: Lloreda). Recuperado de http:/ /www.sic.gov.co/recursos_user/documentos/Jurisdiccionales/Jurisprudencia/ 2012_2/Abreviados/Sentencia\%20No.\%202762\%20de\%202012.doc

México. Suprema Corte de Justicia de la Nación. Segunda Sala (2015). Tesis aislada $2 a$. XL/2015 (10a.). Órgano oficial de publicación de la Universidad Autónoma de Yucatán. Gaceta Universitaria. Recuperado de http://www.abogadogeneral. uady.mx/documentos/Tesis\%20Agosto.pdf 


\section{Conceptos Superintendencia de Industria y Comercio}

Colombia. Superintendencia de Industria y Comercio (2005). Concepto abril 2005 0514398. Radicación 05025708. Trámite 113, Actuación 440, Folios 006. Recuperado de http://www.sic.gov.co/recursos_user/documentos/conceptos/2005/Mayo/ 0525708.php

Colombia. Superintendencia de Industria y Comercio (2011). Asunto Radicación 06007139, Trámite 113, Actuación 440, Folios 004. Recuperado de http:// www.sic.gov.co/recursos_user/historico/d2011sic6021.htm

Colombia. Superintendencia de Industria y Comercio (2011). Asunto Radicación 5015398, Trámite 113 Actuación 440 Folios 007. Recuperado de http://www.sic.gov.co/ recursos_user/historico/d2011sic6452.htm.

\section{Paginas institucionales}

Colombia. Superintendencia de Industria y Comercio. Inicio. Recuperado de http:/ / www.sic.gov.co/drupal/.

Estados Unidos de Norteamérica. Cornell University Law School. Legal information Institute. Recuperado de https://www.law.cornell.edu/supct/html/91971.ZO.html

Chile. Instituto Nacional de Propiedad Industrial (INAPI). Acerca de INAPI. Recuperado de http://www.inapi.cl/portal/institucional/600/w3-propertyname-511.html 